\title{
PROFISSIONAIS DA INFORMAÇÃO E O MAPEAMENTO DO CONHECIMENTO NAS ORGANIZAÇÕES: O CASO DA KPMG BRASIL
}

\section{Nádia M.S. Hommerding \\ Waldomiro Vergueiro}

\section{Resumo:}

Análise e descrição da gestão da Informação nos processos de Gestão do Conhecimento da empresa KPMG Brasil, com ênfase no mapeamento do conhecimento tácito e explícito, buscando disponibilizar/compartilhar as informações mapeadas, por meio da Intranet, ferramenta facilitadora para o compartilhamento e divulgação da informação. Conclui que os Profissionais da Informação têm potencial para liderar e administrar processos de mapeamento do conhecimento nas organizações, principalmente porque possuem especializações inerentes à sua formação, no que concerne a localização, organização, estruturação e disponibilização de dados e informações que, posteriormente, serão transformados em conhecimento. Outra conclusão positiva refere-se ao uso da Tecnologia da Informação, neste caso específico, a Intranet, como aliada no trabalho do bibliotecário.

Palavras-chave:

Profissional da Informação; Gestão do Conhecimento; Intranet; KPMG Brasil

\section{INFORMATION PROFESSIONALS AND THE KNOWLEDGE MAPPING IN ORGANIZATIONS: KPMG BRASIL CASE}

\begin{abstract}
:
Analysis and description of the information management in the processes of Knowledge Management at KPMG Brazil, with an emphasis on the mapping of tacit and explicit knowledge, as well as making available and sharing the mapped information by means of the Intranet, which is an information technology facilitator for the information professional. It concludes that information professionals have potential to lead and manage processes of knowledge mapping in organizations, mainly due to the expertise inherent to their professional education, related to the location, organization, structure, and availability of data and information that will later be transformed into knowledge. Another positive conclusion refers to the use of information technology, in this specific case, the Intranet, as an ally to the librarian's work.
\end{abstract}

Key words:

Information Professionals; Knowledge Management; Intranet; KPMG Brazil 


\section{INTRODUÇÃO}

A evolução tecnológica ocorrida principalmente na última década, aliada à explosão do conhecimento e à necessidade de interação do profissional da informação neste ambiente, originou várias reflexões acerca das possibilidades de contribuição e a discussão sobre as competências necessárias para que os bibliotecários se insiram, de maneira definitiva e eficaz, neste novo ambiente.

Atualmente, considera-se que o conhecimento humano, ou, ainda, o capital intelectual, é o principal ativo das organizações; assim, para desenvolver processos de retenção e mapeamento deste tipo de conhecimento, as empresas que se preocupam em conquistar uma posição de liderança e vantagem competitiva no mercado, independentemente de sua área de atuação, buscam metodologias para caracterização das competências, experiências e práticas em seu ambiente, visando desenvolver processos de identificação, captação e retenção do capital intelectual da organização. Este processo denomina-se Gestão do Conhecimento.

Segundo Davenport (1998), os bibliotecários - que ele denomina de "corretores do conhecimento" - têm importante papel a desenvolver nesse processo. Neste trabalho, pretende-se mostrar, por meio de estudo de caso, a efetiva participação do profissional da informação também no desenvolvimento e na administração da ferramenta para disponibilizar os resultados deste processo de mapeamento, ou seja, por meio da Intranet.

\section{BIBLIOTECÁRIOS X GESTÃO DO CONHECIMENTO}

O conceito de Gestão do Conhecimento surgiu no início da década de 1990 e logo se espalhou. Trata-se de uma ferramenta gerencial para administrar a informação e agregar-lhe valor. Ao filtrá-la, sintetizá-la e resumi-la, ajuda-se os profissionais a conseguir o tipo de informação que necessitam para passar à ação. Trata-se, também, da prática de agregar valor à informação e de distribuí-la. A Gestão do Conhecimento é algo muito mais difícil do que se pode imaginar, principalmente devido à tendência humana de guardar o conhecimento próprio a sete chaves, sem dividi-lo com outros (MANAGEMENT, 1999).

Segundo o Knowledge Management Glossary, Gestão do Conhecimento é “o processo sistemático de procura, seleção, organização, análise e disponibilização da informação, de 
modo que se possibilite aos trabalhadores de uma organização a compreensão necessária e suficiente numa área de interesse específico" (KNOWLEDGE).

De acordo com Davenport e Prusak (1997), muitos bibliotecários e profissionais da Informação já se transformaram em profissionais do conhecimento. Nesse sentido, para a Arthur Andersen apud Chase (1998), os papéis emergentes destes novos profissionais incluem:

Perito Tecnológico - Assegura que os membros da comunidade do conhecimento entendam e utilizem no seu máximo potencial a tecnologia disponível. Trata-se de um papel de liderança e treinamento tecnológico;

Catalogador/Arquivista - Organiza informação que atenda às necessidades da comunidade do conhecimento; organiza a informação numa base de dados, construindo uma base de conhecimento institucional do grupo e melhorando a eficiência;

Guia - Orienta os membros da comunidade do conhecimento a divulgar informação, quando apropriado, e manter alto nível de fontes de informação fora da comunidade;

Explorador - Busca informações úteis para a comunidade do conhecimento, trazendo-as para a base de conhecimento da empresa;

Bibliotecário Pesquisador - Ajuda os usuários a definir suas necessidades de informação, priorizando as informações altamente relevantes, de acordo com as necessidades dos usuários; Analista - Adiciona valor à informação, criando um contexto para o entendimento e trazendo novas questões de interesse para análise e estudo.

Já Skyrme e Amidon apud Chase (1998), criaram uma outra lista de papéis para os profissionais do conhecimento, baseada em suas observações da nova organização intensiva do conhecimento. São eles:

Engenheiro do Conhecimento - Identifica ou mapeia o conhecimento tácito e explícito, para capacitar sua classificação e disseminação;

Editor do Conhecimento - Refina conhecimento explícito em formatos que facilitem subseqüentes acessos e usos. O editor do conhecimento seleciona fontes de informações internas e externas, sintetiza e adapta aos padrões de compartilhamento dentro da organização; 
Analista do Conhecimento - Age como um link entre o cliente interno ou externo e a base do conhecimento. Possui boas habilidades interpessoais, vontade de ajudar os outros e facilidade de comunicação;

Navegador do Conhecimento - Sabe onde os repositórios de informação encontram-se dentro da organização. Em alguns casos, os navegadores do conhecimento agem como mentores para novos analistas do conhecimento.

Coletor de Conhecimento - Acessa fontes externas de conhecimento e as direciona para os clientes dentro da organização. Este papel descreve bem o trabalho dos bibliotecários tradicionais.

Corretor do Conhecimento - Assim como o navegador e coletor, este elemento, usualmente, tem boa rede de contatos dentro e fora da empresa;

Gerente de Ativo do Conhecimento - Identifica, avalia e gerencia um portfólio de ativos do conhecimento, como patentes, marcas, copyright, etc.

Considerando os elementos acima apontados, pode-se argumentar que esses "novos" papéis e funções nada mais são que novos rótulos para trabalhos já existentes. Assim, a emergência da empresa inteligente e o predomínio de trabalhadores do conhecimento como criadores de riqueza podem oferecer aos bibliotecários uma oportunidade única para se reinventarem como profissionais de valor agregado. Muito mais do que se tornarem gerentes do conhecimento, editores ou analistas - e sobreviver com baixos salários dentro da hierarquia da organização, os bibliotecários têm nas mãos a oportunidade para se transformarem em bem pagos "navegadores do conhecimento", conectados, como aranhas, no centro de uma gigantesca rede do conhecimento, uma rede de trabalho eletrônica, composta por clientes internos e externos, experts no assunto, nas bases de conhecimento, etc.

O desempenho desse papel por parte dos bibliotecários torna-se ainda mais importante se considerarmos que, segundo Chase (1998), bibliotecas e Centros de Informação não estão imunes às forças que estão transformando as organizações: de fato, elas são a linha de frente da revolução digital traduzida pela Internet, Intranet, tecnologias multimídia, etc. Hoje, o compartilhamento da informação dentro das organizações é sinônimo de vantagem competitiva e os bibliotecários estão sendo treinados para trabalhar tanto com informação como com o conhecimento, numa variedade de formatos. Os bibliotecários podem entender as diferenças entre informação e conhecimento, e têm antecedentes, conhecimentos técnicos e habilidades para tomar a liderança na criação da empresa inteligente. 
Por outro lado, uma análise das colocações dos autores acima descritos, dentro do contexto da realidade brasileira, leva à reflexão sobre alguns fatores que podem implicar diretamente na possibilidade do profissional da informação assumir papéis de liderança quanto à Gestão do Conhecimento nas organizações. A literatura norte-americana traz inúmeros exemplos de casos nos quais bibliotecários assumem papéis de líderes de equipes ou projetos; no entanto, tal realidade está diretamente relacionada com sua formação acadêmica, que é diferente da formação e do programa curricular no Brasil. Além disso, inúmeros cursos, sejam eles lato ou strictu senso, são regularmente oferecidos aos profissionais norte-americanos, permitindo, assim, um refinamento de suas competências, independentemente de sua graduação (como, por exemplo, o da University of Illinois at Urbana-Champaign, disponível em http://www.lis.uiuc.edu/gslis/degrees/ms.html).

A leitura da bibliografia especializada, particularmente a internacional, permite acreditar na hipótese de que, realmente, o profissional da informação norte-americano está apto a assumir responsabilidades quanto aos processos de desenvolvimento e implantação de Gestão do Conhecimento, bem como de expert ou de instrutor tecnológico, ou seja, aquele que pode definir ou decidir-se pelo uso da melhor tecnologia para disponibilização do conhecimento empresarial. Resta saber, a partir do estudo de caso selecionado para este trabalho, se esta realidade aproxima-se da brasileira, na qual, a uma diferente formação acadêmica agregam-se os fatores econômico-sociais do país, que também divergem, em muito, dos existentes nos Estados Unidos.

Para realização do estudo de caso, foi escolhida a KPMG Auditores Independentes, uma empresa de auditoria e consultoria multinacional, que presta serviços multidisciplinares em diversos segmentos do mercado brasileiro. O estudo foi elaborado por meio de entrevistas com a equipe do Knowledge Center, consulta à homepage da Empresa na Internet, Intranet, publicações internas, troca de e-mails com os funcionários da Empresa e entrevista com a assessora do Diretor-Geral de Conhecimento - $C K O$ e com o próprio $C K O$.

\section{A KPMG AUDITORES INDEPENDENTES}

Com sede em Nova York, a KPMG, cuja denominação representa a abreviação dos nomes de seus principais fundadores, está presente em 159 países e conta com mais de 100.000 
especialistas ao redor do mundo; sua política objetiva oferecer aos clientes soluções e estratégias para enfrentar os desafios de um mercado cada vez mais dinâmico e concorrido (KPMG Brasil).

Dentro de um mercado global e dinâmico, a KPMG tem por meta atuar em antecipação às mudanças econômicas e financeiras em todos os países. Com investimentos em novas tecnologias, no compartilhamento de suas experiências, nos conhecimentos em âmbito global, além de recursos humanos capacitados, a KPMG objetiva ajudar as empresas a se posicionarem e se destacarem na nova economia de informação.

Conforme a Harvard Business School (1997), em 1996 a KPMG reconheceu a Gestão do Conhecimento como o principal fator para atingir vantagem competitiva. Em 1995, a empresa gastou U\$ 95 milhões de dólares em Tecnologia da Informação, somente nos Estados Unidos. Esse orçamento cresceu em 50\% em 1996 e a expectativa era de que esse crescimento continuasse nos próximos 4 anos, conforme a Empresa se preparava para o século XXI.

O KWorld, a ferramenta do conhecimento da KPMG, iniciado em 1997 e concluído no início de 1999, foi a aposta estratégica da Empresa para fazer todas as suas peças trabalharem juntas. A base do projeto tecnológico respeitou a herança da prática de consultoria da KPMG, a qual permaneceu organizada em torno do produto, da indústria e da geografia. Antes do KWorld, os usuários da KPMG tinham de localizar fisicamente o trabalho de um especialista e ler dezenas de documentos sobre o cliente ou o trabalho a ser executado; com o KWorld, a informação precisa está ao alcance no computador do usuário.

A KPMG, em parceria com a Microsoft e Cisco Sistemas, desenvolveu e disponibilizou o KWorld para 47.000 pessoas em apenas 9 meses. No Estados Unidos, apesar do sistema estar em uso somente desde junho de 1999, os executivos da Empresa notaram mudanças significativas na visão dos clientes sobre seus serviços. O KWorld oferece aos clientes um ambiente colaborativo no qual o conhecimento do cliente e o da KPMG atuam em benefício de ambos (MICROSOFT, 1999). 


\section{BREVE HISTÓRICO DA KPMG AUDITORES INDEPENDENTES NO BRASIL}

A KPMG Brasil nasceu da fusão de três empresas com grande tradição na comunidade de negócios: a Klynveld Main Goerdeler, presente no país desde 1982, a Peat Marwick e Mitchell, com atuação desde 1915, e a Roberto Dreyfuss, empresa brasileira fundada em 1943.

Formada em $1^{\text {o }}$ de julho de 1987, a KPMG está presente em 9 cidades do Brasil, com mais de 900 profissionais, 673 profissionais especializados e 239 funcionários da área administrativa. Seus principais serviços são:

1-Assurance (Auditoria) - Para garantir confiança e transparência nos relatórios financeiros destinados à comunidade, a KPMG examina as informações e os dados das empresas com critérios objetivos. Esse enfoque é dado na auditoria de clientes dos mais variados ramos de atividade, enfatizando o entendimento dos negócios, a análise dos riscos e as necessidades específicas, por meio de técnicas modernas, desenvolvidas nacional e internacionalmente. São realizados, também, a avaliação de empresas, os estudos para aquisição, a avaliação de sistemas de controles internos e a preparação de demonstrações financeiras.

2-Financial Advisory Services - FAS (Serviços de Transações Corporativas) -Assessoria em processos de aquisição e fusão. Líder mundial em serviços de transações corporativas, a KPMG foi também contemplada com o primeiro lugar no ranking da Securities Data Company, como líder mundial em assessoria a fusões e aquisições, pelo sexto ano consecutivo. No Brasil, a KPMG Corporate Finance é uma das líderes de mercado, assessorando clientes em várias transações de médio e grande porte, criando um mapeamento do interesse dos investidores internacionais no Brasil, bem como dos planos de expansão dos investidores nacionais. Além da assessoria em fusões e aquisições, oferece serviços nas áreas de avaliações de negócios, recuperação de empresas, investigação de fraudes e diligência.

3 - TAX (Impostos) - Assessoria na interpretação e aplicação das normas tributárias e legais, nos países em que os clientes operam ou desejam operar, analisando mercados e investimentos. Conta com profissionais especializados na execução de auditorias e consultorias fiscais, bem como em planejamentos tributários.

4 - Executive Search \& Career Consulting (Recrutamento e Seleção de Especialistas e Aconselhamento de Carreira) - Consultoria no recrutamento, contratação, motivação, 
avaliação, desenvolvimento, retenção e desligamento de profissionais, observando os fatores produtividade, desempenho e imagem da empresa, interna e externamente.

5 - Consulting (Consultoria) - A KPMG Consulting está totalmente voltada para a competitividade dos clientes na economia digital. Por meio de alianças com empresas de ponta, tais como, Cisco, Microsoft e Federal Express, ela fornece serviços que vão desde a estratégia até a execução de soluções apoiadas na Internet. (KPMG BRASIL)

No Brasil, a sede da KPMG está situada na cidade de São Paulo, possuindo ainda escritórios no Rio de Janeiro, Belo Horizonte, São Carlos, Campinas, Curitiba, Porto Alegre, Brasília e Salvador.

\section{O KWORLD: GESTÃO DO CONHECIMENTO NA KPMG E O KNOWLEDGE CENTER}

Conforme a Harvard Business School (1997) em estudo de caso sobre a empresa, em 1996 a KPMG reconheceu a Gestão do Conhecimento como o principal fator para atingir vantagem competitiva. Em 1995, a Empresa gastou U\$ 95 milhões de dólares em Tecnologia da Informação, somente nos Estados Unidos. Esse orçamento cresceu 50\% em 1996 e a expectativa era de que esse crescimento pudesse continuar nos próximos 4 anos, conforme a Empresa se preparava para o século XXI.

Conforme citado no artigo, de acordo com Allen Frank, Diretor-Geral de Tecnologia e Sócio da KPMG nos Estados Unidos, o objetivo da empresa em 1996 era criar um ambiente de Gestão do Conhecimento que amarrasse o legado de sistemas, uma Intranet, a World Wide Web, a data warehousing, a gerência de documentos e as novas aplicações entre redes de computadores e gerência de redes. O objetivo, desta forma, era dar aos profissionais da KPMG acesso ubíquo e com confiança ao cérebro da empresa. Ainda de acordo com Frank, o ativo real da KPMG era o conhecimento que residia em cada um de seus profissionais. Com 17.000 funcionários distribuídos em 120 escritórios nos Estados Unidos, ele acreditava ser imperativo que a empresa gerenciasse e compartilhasse efetivamente o conhecimento, para prover os melhores serviços possíveis para os clientes.

O Kworld, a ferramenta do conhecimento da KPMG, iniciado em 1997 e concluído no início de 1999, foi a aposta estratégica da empresa para fazer todas as suas peças trabalharem 
juntas. A base do projeto tecnológico respeita a herança da prática de consultoria da KPMG, a qual permanece organizada em torno do produto, da indústria e da geografia.

A manutenção do repositório corrente de informações ocupa "15 editores do conhecimento" em tempo integral no escritório da KPMG da cidade de Nova York. Os editores capturam conhecimento não quantificável de alimentadores que lhes encaminham, eletronicamente, cerca de 8.000 documentos diários, entre textos de livros e revistas, discursos, propostas, etc. (GLASSER, 1999).

\section{O KNOWLEDGE CENTER E A GESTÃO DO CONHECIMENTO NA KPMG BRASIL}

Atualmente, o Knowledge Center da KPMG Brasil constitui um departamento integrado às atividades da empresa. Esta integração ocorreu em função do desenvolvimento departamental, iniciado durante o final da década de 90.

\subsection{Organização}

Em meados de 1999, após a definição de um plano que incluiu objetivos, público-alvo e processos de implantação da Gestão do Conhecimento no Brasil, a KPMG Brasil decidiu se juntar à KPMG Internacional em sua comunidade de compartilhamento de conhecimento, por meio da ferramenta KWorld. Essa decisão foi aprovada pelos membros do Comitê Executivo no Brasil e representou um compromisso para compartilhar experiência, bem como rever localmente a segurança da informação, a infra-estrutura e a alocação de tempo e pessoas para o projeto. Por essa ocasião, decidiu-se que o departamento chamado de Knowledge Center da empresa seria o responsável operacional pela implantação de tal estratégia.

Já antes disso, em 1997, a biblioteca foi objeto de uma mudança física para o piso térreo do edifício que ocupa atualmente e passou por um processo de renovação de serviços e produtos oferecidos, o que a levou a ter uma mudança e atualização no nome, de acordo com a realidade da empresa, passando a ser denominada, desde então como Knowledge Center.

Até o início de 2000, o departamento encontrava-se solto, ou seja, sem uma estruturação oficial vinculada a alguma diretoria dentro do organograma. Ficou muito tempo sob a 
orientação da área de Impostos, depois da de Auditoria. Em janeiro de 2000, com a vinda do Diretor-Geral de Conhecimento - Chief Knowledge Officer (CKO) -, uma nova diretoria, denominada Gestão do Conhecimento - Knowledge Management -, foi criada, com Knowledge Center sendo oficializado dentro dessa diretoria.

\section{Organograma Knowledge Management}

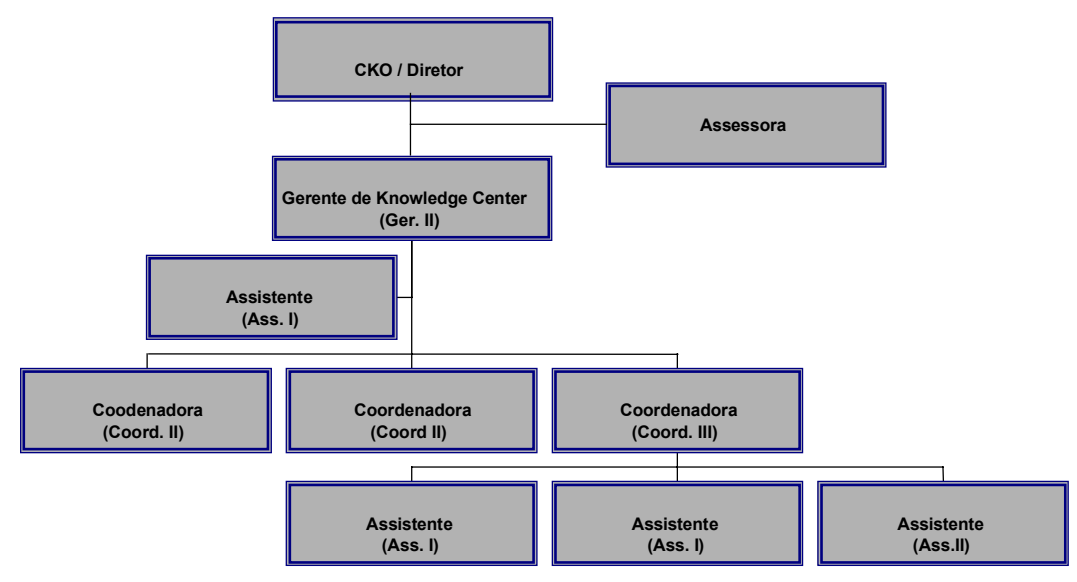

\section{FIGURA 1 - Organograma do Knowledge Center}

Sob a gerência de uma bibliotecária, que se reporta diretamente ao $C K O$, o Knowledge Center (Centro de Conhecimento) da KPMG Brasil passou a ser uma central de informações, atendendo e dando suporte informacional a todas as áreas de negócios da empresa, ou seja, Auditoria, Consultoria, Finanças Corporativas, Jurídica e Administração. Além desses clientes internos, atende ainda às solicitações de clientes da empresa.

Atualmente, conta com uma infra-estrutura de recursos humanos de nove pessoas, entre gerente, coordenadoras, bibliotecárias, assistentes, estagiários e trainee, conforme se vê pelo Quadro 1: 


\section{Quadro 1 - Equipe de Trabalho do Knowledge Center}

\begin{tabular}{|c|c|}
\hline $\begin{array}{l}\text { Cargo/Tempo de } \\
\text { Experiência na empresa }\end{array}$ & Formação Acadêmica \\
\hline $\begin{array}{l}\text { Gerente } \\
22 \text { anos }\end{array}$ & $\begin{array}{l}\text { Biblioteconomia - Especialização em Direito Tributário - } \\
\text { Ciências das Finanças }\end{array}$ \\
\hline $\begin{array}{l}\text { Coordenadora } \\
\text { (economista) } \\
16 \text { anos }\end{array}$ & $\begin{array}{l}\text { Economista - Pós-Graduação em Gerenciamento e } \\
\text { Planejamento de Sistemas de Informação Automatizada }\end{array}$ \\
\hline $\begin{array}{l}\text { Bibliotecária } \\
8 \text { anos }\end{array}$ & Biblioteconomia - Atua na área tributária \\
\hline $\begin{array}{l}\text { Coordenadora } \\
\text { (bibliotecária) } \\
2 \text { meses }\end{array}$ & $\begin{array}{l}\text { Biblioteconomia - Pós-Graduação em Gerenciamento e } \\
\text { Planejamento de Sistemas de Informação Automatizada }\end{array}$ \\
\hline $\begin{array}{l}\text { Assistente } \\
4 \text { anos }\end{array}$ & Estudante de Direito \\
\hline $\begin{array}{l}\text { Assistente } \\
5 \text { anos }\end{array}$ & Estudante de Direito \\
\hline $\begin{array}{l}\text { Assistente } \\
1 \text { ano }\end{array}$ & Estudante de Administração de Empresas \\
\hline $\begin{array}{l}\text { Trainee } \\
1 \text { ano }\end{array}$ & Administração de Empresas \\
\hline $\begin{array}{l}\text { Estagiária } \\
6 \text { meses }\end{array}$ & $\begin{array}{l}\text { Estudante de Administração de Empresas e Comércio } \\
\text { Exterior }\end{array}$ \\
\hline
\end{tabular}

Assim, como é possível observar no quadro anterior, a equipe de trabalho do Knowledge Center é composta por pessoas com formações variadas, o que é considerado muito positivo pela Bibliotecária-Gerente. Segundo ela, os conhecimentos distintos levam a uma complementação das "expertises" particulares de cada indivíduo, beneficiando o departamento como um todo.

A diversificação de conhecimento parece ser também essencial devido ao Knowledge Center prover de informações todas as linhas de negócios da empresa, seja na matriz localizada em São Paulo ou nos escritórios espalhados pelo Brasil. Acumula, ainda, as funções de organizador e provedor de informações relacionadas à Gestão do Conhecimento na KPMG Brasil, disponibilizando no Kworld informações encaminhadas por todos os escritórios do País.

O departamento, além de ser o responsável pelo repositório de informações da empresa - pois a publicação e a manutenção das informações de todas as unidades de negócios no KWorld é uma de suas atribuições -, é também um veículo de transformação e geração de conhecimento 
por meio das informações que disponibiliza. Suas atividades podem ser resumidas em cinco funções principais:

-Responsabiliza-se pela seleção, organização e disponibilização de informações secundárias obtidas na mídia em geral (informações de mercado);

-Acompanha os cenários econômico, financeiro e tributário, direcionando a divulgação das informações para as respectivas áreas de interesse (informação dirigida);

-Elabora trabalhos e pesquisas, objetivando operar como apoio e facilitador para todos os departamentos e escritórios da Empresa no Brasil;

-Organiza e disponibiliza as informações da Empresa, por meio da ferramenta de Gestão do Conhecimento - Kworld - acessível por meio da Intranet;

-Orienta a pesquisa de informações dentro do KWorld, atuando como facilitador.

Entre os serviços do Knowledge Center, destacam-se os listados no Quadro 2, conforme entrevista realizada com os funcionários em agosto de 2001: 


\section{Quadro 2 - Produtos e Serviços do Knowledge Center}

TIPO DETALHAMENTO

Clipping impresso $e$ eletrônico

Pesquisas técnicas

Elaboração de trabalhos específicos

Aquisição de publicações

Serviços ou Processos Técnicos

Desenvolvimento de banco de dados
Clipping impresso - Notícias de interesse da KPMG e de clientes da Empresa. As notícias são selecionadas dos jornais e revistas e são encaminhadas de acordo com a área de interesse;

Clipping eletrônico/descanso de tela - As manchetes das principais notícias são editadas e, por meio de software específico, disponibilizadas na tela de descanso da Intranet.

Enfocando as áreas financeira, tributária, de seguros, balanços e demonstrações financeiras das empresas de capital aberto e fechado de todos os setores (alimentos, bebidas, telecomunicações, químico, fusões e aquisições, bens de capital, etc.), leis, normas, etc.

Market share;

Listagem de empresas falidas e concordatárias;

Controle de balanços das empresas do mercado;

Acompanhamento de licitações e fornecimento de editais;

Acompanhamento técnico e atualização diária de legislação, jurisprudência e leitura de diários oficiais

Sugestão de leitura para as diferentes áreas, das publicações disponíveis no próprio KWorld, buscando incentivar o uso deste.

Acompanhamento de índices financeiros e elaboração de tabelas de cálculos específicos.

Atendimento ao usuário Realizado por telefone, e-mail e pessoalmente;

Empréstimo de livros e publicações em geral; Fornecimento de taxas e índices de referência (dólar, IPC);

Orientação para uso e localização das publicações no departamento.

Análise das solicitações feitas pelos usuários e aquisição destas após aprovação pelo sócio da área;

Renovação de jornais e revistas para todas as áreas da Empresa.

Classificação e catalogação de livros técnicos nas áreas de auditoria, contabilidade, direito e informática (uso da CDU);

Registro e controle da chegada de revistas, boletins e jornais;

Atualização de boletins e legislação em formato impresso;

Organização física do material nas estantes, guarda de livros, boletins, revistas, jornais e demais materiais consultados.

Atualmente encontra-se em desenvolvimento estudo para adoção de um sistema único, centralizador, que 
vai atender às necessidades específicas do Knowledge Center e seus clientes internos, agrupando em uma única base de dados, os diferentes bancos de dados do departamento, visando facilitar o acesso e integração das informações. Existe uma parceria com a área de Suporte Tecnológico na análise e aprovação desta ferramenta desenvolvida por uma consultoria externa.

Distribuição/controle de Diariamente chegam revistas, livros, periódicos e material - local e do exterior relatórios que precisam ser distribuídos no Brasil para os respectivos departamentos e escritórios, bem como serem encaminhados para o exterior.

Suporte - Conteúdo do KWorld (intranet internacional) Publicação dos relatórios, análises, propostas, encaminhadas pelas diversas áreas da Empresa na Intranet da Empresa, por meio do KWorld; Atualização dos conteúdos já publicados.

Orientação para uso do Kworld Orientação aos usuários para uso e localização das informações na Intranet, usando a ferramenta de Gestão do Conhecimento da Empresa, o KWorld.

\subsection{Atuação do Knowledge Center nos processos de Gestão do Conhecimento da KPMG}

O Knowledge Center possui ampla atuação como área gestora dos fluxos de informação da KPMG Brasil. Além de oferecer os produtos e serviços de uma biblioteca tradicional, tanto o departamento quanto os funcionários que nele atuam encontram-se também fortemente engajados nos processos de Gestão do Conhecimento da empresa. O departamento atua no gerenciamento de informações externas e internas à KPMG, estas últimas compreendendo a documentação gerada na empresa (documentos, informação e conhecimento). Observa-se um enfoque mais acentuado em relação ao conhecimento do que ao acervo propriamente dito.

Quando da definição das estratégias de implantação de Gestão do Conhecimento na KPMG, bem como da ferramenta para disponibilização deste conhecimento, o Kworld tornou-se vital à definição de como seria o fluxo interno de serviço, uma vez que era imperativo um acordo entre todas as áreas envolvidas para iniciar os trabalhos. Após acessar a ferramenta mundial KWorld, por meio de uma conexão especial, e realizar uma navegação inicial com o intuito de melhor conhecê-la, foi detectado que era necessário um fluxo local que trouxesse benefícios específicos, tais como: 
-Controlar constantemente a publicação do documento;

-Evitar diferentes formatos relativos a conteúdos publicados pelas diferentes áreas de negócios do Brasil;

-Dar suporte às diferentes áreas de negócio para manutenção das atualizações das publicações;

-Dar suporte tanto quanto possível às áreas de negócio, no que se referia à parte operacional das publicações de conteúdo do KWorld;

-Ajudar as áreas de negócio quanto ao tempo que elas teriam de dedicar ao KWorld.

Uma vez que o Knowledge Center foi definido para reportar-se à área de Gestão do Conhecimento no Brasil, decidiu-se que o fluxo de publicação de conteúdo ocorreria conforme a figura 2, abaixo:

\section{FIGURA 2- Fluxo de Publicação de Conteúdo}

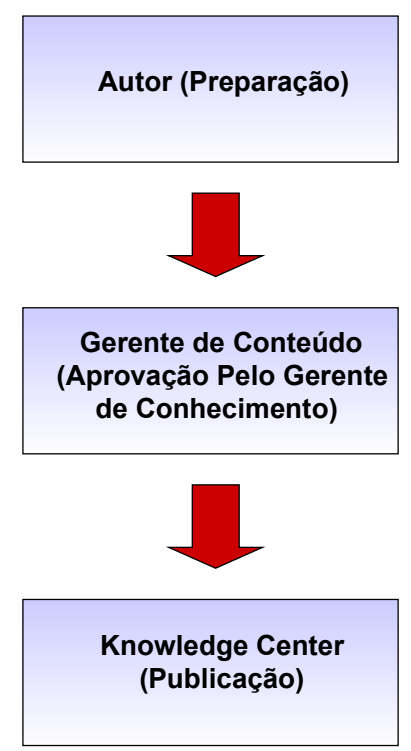

Com esta estrutura, o Knowledge Center tornou-se a área responsável pelas atividades e relatórios de acesso e uso ao KWorld. O contato entre o Knowledge Center e as diferentes áreas de negócios foi centralizado nos Gerentes de Conteúdo das respectivas áreas, com o intuito de evitar duplicidade de comunicação. 
Os profissionais do Knowledge Center estão fortemente engajados no processo de implantação de Gestão do Conhecimento na organização. Apesar de ser uma nova proposta, e, conseqüentemente, estar ainda num processo de adaptação às novas exigências e responsabilidades foi observada uma postura bastante positiva e receptiva por parte desses profissionais quanto aos novos desafios que se apresentam diariamente. Como já comentado anteriormente, a tarefa de mapeamento do conhecimento não é das mais fáceis, pois existe a resistência natural das pessoas de se oporem à democratização de seu conhecimento. Além disso, a mudança cultural imposta na organização ocorre lentamente, o que exige paciência, persistência e elaboração de fluxos de trabalho que contemplem resultados ao longo do tempo.

Em relação à Intranet, para a equipe do Knowledge Center não há dúvidas quanto aos benefícios que ela trouxe em relação aos processos de disponibilização da informação na KPMG Brasil. Com o aumento do fluxo de trabalho no Knowledge Center, decorrente da implantação da Gestão do Conhecimento na empresa, a Intranet tornou-se uma ferramenta aliada para publicação das informações e, conseqüentemente, transformação dessas informações em conhecimento pelos usuários do KWorld.

\section{CONCLUSÕES}

A atuação do Knowledge Center como órgão facilitador do fluxo de informações da Empresa, visando à geração de conhecimento propriamente dita, é essencial para a afirmação da importância da área dentro da organização, bem como um desafio a ser transposto no que se refere à inovação e ao compromisso com novas responsabilidades que surjam. A utilização das tecnologias da informação como elemento facilitador das novas atividades do profissional da informação apresenta-se, nesse sentido, fundamental para melhor organização do trabalho. No caso específico analisado neste artigo, tal tecnologia reflete-se no uso da Intranet, sendo não somente um meio facilitador do trabalho, mas, também, um auxiliar para os processos de organização, estruturação, apresentação e disponibilização de dados e informações, os quais, posteriormente, irão transformar-se em conhecimento.

Por se tratar de uma metodologia e de uma sistematização de dados, informações e conhecimento, a Gestão do Conhecimento envolve ações de identificação, coleta, armazenamento/catalogação, disponibilização, compartilhamento, adaptação e uso de 
informações que estão na mente das pessoas que compõem uma organização. Nenhum desses conceitos é desconhecido do jargão biblioteconômico, mas, sim, de domínio da área. Assim, observa-se que autores de peso como Davenport e Prusak (1998), Sveiby (1988) e várias empresas de consultoria internacionais, como a Arthur Andersen, citam os bibliotecários como profissionais potenciais para assumir um papel de liderança dentro da Gestão do Conhecimento nas empresas, chegando a denominá-los, dentro desta nova realidade, como corretores do conhecimento e/ou profissionais do conhecimento.

Nesse contexto, o bibliotecário, como profissional especializado no gerenciamento de Sistemas de Informação, detém a metodologia e know-how para desenvolver e colaborar na Gestão do Conhecimento. Além disso, o trato com o usuário, aquele que busca a informação com os profissionais da informação, é uma atividade desenvolvida já há longa data, constituindo-se mesmo na essência da própria ciência da informação e fazendo com que os bibliotecários trafeguem confortavelmente por esse ambiente.

A prática dos profissionais do Knowledge Center da KPMG sinaliza para a confirmação das afirmativas acima. Podemos concluir, então, que o bibliotecário possui qualidades e aptidões que facilitam, em muito, o trabalho de mapeamento das pessoas dentro de uma organização, tornando-se seu grande aliado na gestão do conhecimento. No entanto, ainda que a identificação, o compartilhamento e a disponibilização do conhecimento para toda a organização sejam tarefas mais do que inerentes ao profissional da informação, é possível indagar porque esse espaço não é ocupado de forma mais efetiva pelos profissionais da informação.

A resposta a esse questionamento pode envolver elementos relacionados tanto a competências pessoais como a atributos intelectuais, comportamentos técnicos, e, principalmente, de relacionamento pessoal nas organizações, que, muitas vezes, representam barreiras à efetiva participação dos Profissionais da Informação nos processos de Gestão do Conhecimento nas empresas. Por outro lado, parece evidente que o profissional da Informação pode não ser o único elemento mais adequado para definir a publicação e o compartilhamento de documentos; para isso, existe já prevista dentro da metodologia da Gestão do Conhecimento a figura dos gerentes de conteúdo, normalmente uma pessoa técnica ou com nível gerencial e de diretoria, que autoriza a publicação das informações, via Intranet, para acesso interno. Isso não significa, porém, que o profissional da Informação não possa assumir esta 
responsabilidade; é necessário, no entanto, o estabelecimento de políticas internas quanto à publicação de informações.

No estudo de caso realizado na KPMG Brasil, pode-se observar que o perfil do profissional da informação é um fator de extrema importância para a ampliação do seu espaço de atuação nas empresas, principalmente em atividades menos convencionais. Observou-se, também, que uma série de atributos tem influência direta na atuação dos profissionais da Informação em processos de atuação na Gestão do Conhecimento e uso/conhecimento de tecnologias. Esses atributos relacionam-se a fatores comportamentais, técnicos e intelectuais, tendo um impacto direto no perfil desejado do profissional da Informação.

O estudo de caso também corroborou a existência de um espaço de excelência para atuação do profissional da informação, aquele de mapeamento das pessoas e de suas competências, num nível mais técnico do que propriamente estratégico. O conjunto de competências de um indivíduo, sua formação acadêmica, cursos de especialização, idiomas, relacionamento pessoais e cognitivos vai gerar informação estratégica e planos estratégicos para a organização. No entanto, não é tarefa das mais fáceis mapear este conhecimento tácito e tentar explicitá-lo, mesmo porque o conhecimento de cada pessoa está relacionado com as suas vivências. Porém, na medida em que os profissionais da informação se capacitarem para a identificação e estruturação de inúmeras informações sobre os diversos participantes da organização, delineando seus perfis, estarão colaborando exatamente num aspecto da gestão do conhecimento que as empresas buscam sistematizar. Desta forma, eles estarão não apenas trazendo uma efetiva colaboração à estratégia organizacional como, ao mesmo tempo, aumentando seu valor para a empresa.

\section{REFERÊNCIAS}

CHASE, R. L. Knowledge navigators. Information Outlook, v. 2, n. 9, p. 17- 26, September 1998.

DAVENPORT, T. H. (1996). Knowledge management case study. Disponível em: $<$ http://www.bus.utexas.edu/kman/hpcase.htm $>$ Acesso em: 03 maio 2001.

; PRUSAK, L. Conhecimento empresarial: como as organizações

gerenciam o seu capital intelectual. Rio de Janeiro: Campus, 1998. 237 p.

; LONG, D. W., BEERS, M. C. Successfull Knowledge Management

Projects. Sloan Management Review, Winter 1998. 
HARVARD BUSINESS SCHOOL. Kpmg peat Marwick U.S.: one giant brain. Boston: Harvard Business School Publishing, 1997. [Study case 9-397-108]

HOMMERDING, N. M. S. O profissional da informação e a gestão do conhecimento nas empresas: um novo espaço para atuação, com ênfase nos processos de mapeamento do conhecimento e disponibilização por meio da Intranet, 2001. $210 \mathrm{f}$. Tese (Mestrado) - Escola de Comunicações e Artes, Universidade de São Paulo, São Paulo, 2001.

KNOWLEDGE management glossary. Disponível em:

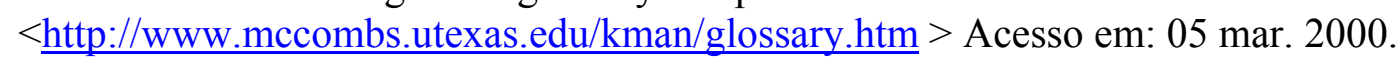

KPMG AUDITORES INDEPENDENTES. Kworld deployment: the brazilian experience. São Paulo: KPMG, October 2000. 15 p.

KPMG AUDITORES INDEPENDENTES. Informativo Kworld, n. 1, jan. 2001. Informativo Kworld, n. 2, jan. 2001.

KPMG BRASIL. Disponível em: <http:// www.kpmg.com.br>. Acesso em: jun. 2003.

MANAGEMENT review, December 1999. Disponível em: <http://www.amanet.org>.

MICROSOFT. KPMG turns Knowledge into value with Kworld. Disponível em: $<$ http:// www.microsoft/knowledge/kworld.html $>$. Acesso em: 09 jun. 2001.

SVEIBY, K. E. A nova riqueza das organizações. Rio de janeiro: Campus, 1998.

UNIVERSITY OF ILLINOIS AT URBANA- CHAMPAIGN. Master of Science Degree

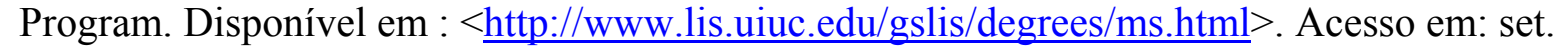
2003. 


\section{NÁDIA M.S. HOMMERDING}

Coordenadora da Área de Desenvolvimento do Modelo da Biblioteca Virtual em Saúde do Centro Latino Americano e do Caribe de Informação em Ciências da Saúde (BIREME). Mestre em Ciências da Comunicação pela Escola de Comunicações e Artes da Universidade de São Paulo (ECA-USP). Av. Prof. Lúcio Martins Rodrigues, 443 - Cidade Universitária, SP, Brasil. 05508-900

E-mail: hommerdi@bireme.br

\section{WALDOMIRO VERGUEIRO}

Professor Associado e Chefe do Departamento de Biblioteconomia e Documentação da ECA-USP. Av. Prof. Lúcio Martins Rodrigues, 443 - Cidade Universitária, SP, Brasil. 05508-900

E-mail: wdcsverg@usp.br

Artigo aceito para publicação em: 01/05/2004 